\title{
"Models and Realities": An Introduction
}

\author{
SYED NAWAB HAIDER NAQVI*
}

This is the first of a series of symposia we are organizing in the pages of the Pakistan Development Review to fix our gaze on the twilight zone lying between the theory and the practice of development economics. In the Autumn of 1979-I must confess, not without a tinge of autumnal depression-I had addressed letters to about 50 scholars working in this general area announcing that "it is proposed to bring out symposium issues of the Pakistan Development Review focusing on the State of Development Economics, which in the opinion of many has not yet attained its 'steady-state'. It is, therefore, essential to have a second (or $n$ th!) look at the state of the art in the general area of development economics, not only to satisfy our academic appetite and to whet it a little bit more, but also to provide proper guidelines for policy formulation". Those who responded to this request did so enthusiastically, supporting the general idea expressed in the letter. Considering the exceedingly busy schedule that economists keep these days, the outcome of my appeal has been gratifying-even though the 'utility function', appropriately discounted by a 'time-paucity' factor, has still not been optimized! On the basis of the contributions already received as well as of those confidently expected soon, we should be able to bring out at least three special symposium issues, devoted to the "State of Development Economics: Models and Realities". The present issue includes papers by outstanding scholars like Jan Tinbergen, Sukhamoy Chakravarty, Paul Streeten, Anthony Bottomley, Pan Yotopoulos and Amit Bhaduri. The coming issues of the Pakistan Development Review will include longer papers on some of the problems touched upon in the present collection and on such basic questions as the choice of techniques, trade policy, economic-demographic modelling, urban-rural and international migrations, etc.

The contributions by Tinbergen, Chakravarty and Bhaduri, included in the present issue, make it quite clear that growth models are-in fact, have been-highly relevant for development planning. One of the contributions of growth theory has been that it has provided us with an "analytic filing system", à la Friedman, or with a "language", promoting systematic and organized thinking, à la Marshall. However, 
if its utility were to rest mainly on its educative role, then this would not be enough justification for the economist's insistence that the policy-makers did need growth theory more than they normally do-that is not at all! For having succumbed to the economist's logic, what should the 'madman in authority' make of the endless debate about one 'filing system' being superior to another? And if it is asserted that for educative purposes it does not matter which version is superior, then the 'filing system' ceases to be even of any epistemological interest. The real worth of growth theory, as Chakravarty shows, is that it represents a body of suggestive hypotheses which help us not only to understand the highly complex reality of economic growth but also to make valid 'predictions' about the entire growth path, once the initial conditions are specified. It is in this context that even such seemingly esoteric concepts of growth economics as 'steady-state' and the turnpike theorems provide important guidelines to policy makers in their task of charting out the best possible strategy for development-or, in the somewhat opaque language of the growth theorists, in delineating optimal trajectories of consumption, investment and output. A more direct application of the growth models is exemplified by the use of the two-sector, 'closed' Mahalanobis-Fel'dman model, involving non-shiftable capital stock, to determine the policy choice about the size of the restraints to be imposed on 'initial' consumption. Such a conceptualization of the development process has dictated a strategy which puts a premium, at the initial stages of planning, on a heavy investment in capital-goods producing sector, with a view to maximizing the consumption stream-more precisely, an appropriately chosen utility functional-over the planning horizon, finite or infinite. Furthermore, Tinbergen informs us that the message of the Harrod-Domar model has found a distinctly audible echo in various development models, influencing the overall strategy of planning as well as inspiring several simplifying techniques like "planning in stages", and sectoral, regional and 'functional' planning models.

However, models of this class tell us nothing about the 'composition'-i.e. the division between profits and wages-of the consumption stream so maximized. This is an important omission because one cannot be complacent, at least at the policy-making level, about the implicit distributive bias of the optimal consumption turnpike. There is a real danger that such a strategy, in the event of a (certain) failure to coax out enough domestic saving, may lead to the adoption of a set of policies involving an increasing reliance on "profit inflation" for financing high level of investment, thereby having an adverse effect on the distribution of income-a problem discussed at length by Bhaduri. (This sequence of events is more likely to occur within a closed-economy framework, which rules out the possibility of foreigncapital inflows.) Accordingly, it is important that growth models should explicitly link economic growth with the process of income distribution so that the planning exercises consist "not only of an investment plan, but also of a plan for controlling the process of income generation". Not only that. The effect of the 'opening' up of the habitually closed two-sector growth models on the optimal trajectories of consumption, investment and output should also be studied because in that event the capital-goods sector will not be that crucial for the optimal solution-indeed the optimal solution may itself improve because of the easing of one of the binding constraints.

Furthermore, considering the facts that foreign-capital inflows can no longer be taken for granted to fill the gap between planned investment and planned saving because of the changing politics of foreign aid, that low per capita income in developing countries puts a definite limit on their capacity to raise substantially the marginal rate of savings and that these countries remain committed to the goal of selfreliance, the wisdom is suspect of pursuing policies-inspired mainly by the Mahalanobis-Fel'dman type models-which have the effect of substantially raising the capital/output ratio in an environment of extreme capital scarcity, particularly in the initial period, to achieve high growth rates. One may wonder if a conscious policy of lowering the capital/output ratios, mainly through technological change, to help achieve high growth rates is not the more appropriate one for the developing countries to pursue-particularly for those which require the export sector to contribute significantly to the growth process. This problem has not been faced by the contributors to this symposium, but is of considerable importance for practical policymaking.

Apart from the question of interpreting-or shall we say 'decoding'-the oblique signals coming from the stratosphere of growth theory, it is important, as Tinbergen argues, that the growth models should be broadened in scope by the explicit inclusion of additional variables. This needs to be done for analysing in both quantitative and qualitative terms the problems of income distribution, the performance of the 'informal sector', the ecological decay caused by factors like deforestation and air pollution, etc. Some attempts, mostly illustrative, have recently been made-e.g. Ahluwalia and Chenery's, "A model of Distribution and Growth" in Redistribution with Growth (1974)-to extend the existing multi-sectoral models, through the basic concept of a "segmented economy", by allowing for a unified treatment of the growth and distribution of different socio-economic groups, with higher weights assigned to the consumption of the low-income "segment" of the economy. Such extensions of the formal models are essential because 'mental models' and qualitative judgements can at best provide a partial picture of the complex relationships among the various variables, both direct and indirect, that determine not only the rate but also the composition of economic growth. However, such a 'broadening' of the basic model cannot go on beyond a certain point. The problems of mathematical complexity and the high marginal computational costs of the inclusion of additional variables-and Tinbergen knows more about them than any other living economist does-should not be taken lightly because as Samuelson, quoting the famous biologist Peter Medawar, points out: "Science must deal with that which can be managed, eschewing the intractable". Furthermore, models 
cannot be made to portray reality too faithfully without ending up in pure 'noise'. If these models become too arcane to be comprehended by ordinary mortals, then they will no longer remain "benchmarks for carrying out a dialogue between the planners and the policy-makers". This would be bad luck for the models (and the model builders as well) because it takes an animated practical application to rescue them from the deactivating influence of mathematical finesse.

Another extension-or is it a rejection?-of the basic model has been inspired by the concern of development economists that, thanks to the development strategy so far pursued, the fruits of economic development have not normally trickled down to those living below the "poverty line"-which is drawn differently as well as indifferently by various authors. Even though Kuznets's hypothesis may tempt us to take stoically the increasing relative income inequality which the process of economic development has 'historically' brought in its train, the secular worsening of absolute poverty-i.e. the lot of the poorest 40 percent-cannot be blithely glossed over as a minor detail of the dynamics of growth. Deliberate policies, involving an acceleration of the GNP growth rates and a greater emphasis on income-equalizing and population-restricting policies, will have to be taken to alleviate extreme, socially intolerable poverty levels. The so-called basic-needs approach, outlined briefly in Paul Streeten's paper, builds on this theme and attempts to provide guidelines for a development strategy which aims at eliminating the worst forms of poverty by enabling the poor to gain "access to minimum levels of consumption of certain basic goods and services". (The papers by Szal and Standing appearing in the Autumn issue of the Pakistan Development Review explore the basic-needs approach in greater detail.) Much remains to be done to develop properly the theoretical foundations of this concept to prevent its otherwise certain degeneration into some kind of fetishism for increasing expenditures on health, housing and water. It is important to recognize that, while growth and distribution may reinforce each other for sometime, the inevitable trade-off between these two magnitudes is bound to raise its ugly head at some specific point along the growth path. The task of the basic-needs theorist is a convincing demonstration of the superiority of the proposed development strategy over all other strategies by clearly establishing on a priori grounds that, in a growing economy, some provision of basic needs is unambiguously better than none for any arbitrarily chosen dynamic social-welfare function-on the pattern of the proof given by trade theorists that some trade is better than no trade. For it is indeed a triviality to merely assert that some provision of basic needs may improve intertemporal social welfare. However, the basic message of this approach comes out loud and clear. Economic growth does not have much meaning if it makes only an in direct and 'potential' contribution to the problem of poverty, which is the major pollutant of the socio-economic environment in the developing countries.

A specific aspect of the general basic-needs approach relates to the issue of devising appropriate strategies for meeting basic food needs. Analytical difficulties in tackling this problem arise from the fact that the growth rate of food output is determined by the interaction of a host of institutional, physical, agronomic and economic variables, which should all be hierarchically 'ordered' within a single model or a connected set of models, particularly the "economic-agronomic interface". A highly promising approach to this intricate problem is the one being pursued at the Centre for World Food Studies, Amsterdam. The Autumn 1980 issue of the Pakistan Development Review contains the Centre's contribution, entitled "Global Modelling of Food and Agriculture".

Another extension of the growth models is an explicit inclusion of the demographic variables like fertility, age structure of the population, mortality and migration, in order to study their direct and indirect effects on the process of socio-economic change. The macro-economic variables-e.g. investment, production, foreign trade-are linked in a multi-dimensional relationship, through 'feedback' effects, with micro-demographic variables-e.g. household consumption, fertility, education, labour force participation, etc. For example, the consumption behaviour of the household is not unrelated to the composition of the family; the supply of labour, and consequently the wage level, is directly influenced by urban-rural migration of labour force, which in turn is determined by levels of income, the number of children and education. Hence, Pan Yotopoulos has emphasized that for a 'complete' analysis there is a need-indeed, a basic need!-of not only "going from development to demography" but also of going the other way round-i.e. "from demography to development"-in order to promote an integrated analysis of the demographic, production and consumption behaviours and the household-in particular the agricultural household, which is "characterized by a simultaneous triple decision-making process that determines the size of the family, the production function and the consumption function".

A synthesis of the economic and the demographic variables within a single formal analytical framework is a difficult task, though one with a considerable potential. While informed qualitative judgements are essential building blocks of any systematic analysis of the complex relation between population and growth, one cannot go very far along this road. To make any progress at all it is essential to build testable hypotheses for conducting 'structural' analysis of the relationships among the economic and the demographic variables, and, even more fundamentally, to make valid forecasts about the interspatial and intertemporal changes in these variables. Hence the need of simulated economic-demographic exercises to capture a socioeconomic reality so complex and baffling and to chart out alternative development strategies as a basis of policy evaluation. Some attempts at economic-demographic model building-e.g. the Bachue model for the Philippines and Kenya-are being made. An interesting contribution by Wery and Rodgers, coming out in the Autumn 1980 issue, analyses in detail the problems of "endogenizing demographic variables" in a formal economic-demographic model.

The most important contribution of the growth models, as this symposium brings out clearly, lies in promoting a systematic way of thinking among both the 
professionals and the policy-makers about the problems of economic development. Indeed, Hicks called growth theory, above all, a dynamic method of analysis. Chakravarty points out that development planning should more fundamentally be seen as an example of what Lowe calls "instrumental inference", providing invaluable guidance on the choice of specific policies required for the attainment of pre-assigned goals and objectives. It is interesting to recall here the reservation expressed by Bottomley about the utility of what he calls "structural growth economics"-that the factors upon which economic theory throws light dn not, of themselves, "furnish the spirit of the times which is the essence of economic growth". However, this is not to say that these factors are irrelevant for promoting economic development. For if this were so, then only charlatans will be called upon, as they sometimes are, to advise on economic matters.

The various contributions contained in this symposium, and in the symposia coming up subsequently, should have a sobering effect on the impatient policymaker who instinctively jumps at ready-made, instant cure-alls-even those which bring disaster in their wake. It is important to recognize "that there are certain vertical and horizontal relations of compatibility which a growing economy must necessarily obey". The process of economic development, like love, is a manysplendoured thing-sharing both its sweet and sour moments. It is, therefore, essential that the multi-dimensional character of the development phenomenon is clearly understood to avoid the mistake-and the frustration that follows-of trying to find easy answers to difficult problems. However, the symposium also has a reassuring message to offer to the 'lay' policy-maker: that the economist can lend a helping hand not only in deciphering the hieroglyphs of growth economics but also in devising appropriate policies to solve the perennial problems of want, poverty and economic deprivation. 